\title{
On Strawsonian contexts ${ }^{\star}$
}

\author{
Varol Akman \\ Bilkent University, Ankara
}

\begin{abstract}
P.F. Strawson proposed in the early seventies a threefold distinction regarding how context bears on the meaning of 'what is said' when a sentence is uttered. The proposal was somewhat tentative and, being aware of this aspect, Strawson himself raised various questions to make it more adequate. In this paper, we review Strawson's scheme, note his concerns, and add some of our own. We also defend its essence and recommend it as an insightful entry point $r e$ the interplay of intended meaning and context.
\end{abstract}

Keywords: context, disambiguation, illocutionary force, indexical, literary theory, meaning, reference, translation, 'what is said'

Being endless, the burden of context is too difficult to bear. It is the sort of burden with which one should learn to live intelligently rather than expect to think away.

Ben-Ami Scharfstein (1989:185)

\section{Introduction}

In human communication using natural language, there is potential for a certain intricacy regarding the communicative mode and 'what is said' (Ziff 1972). The following anecdote comes from Johnson-Laird (1990: 7):

Once upon a time Stalin read out in public a telegram from Trotsky: 'You were right and I was wrong. You are the true heir of Lenin. I should apologize. Trotsky'. According to Leo Rosten, a Jewish tailor then stepped from the crowd and explained to Stalin how he ought to have read the message: You were right and I was wrong? You are the true heir of Lenin? I should apologize???!!

While one appreciates the crucial role of intonation in this story, most of us also realize that it is the historical background through which the intended meaning is contextually determined in this case. Thus, Stalin's rendering of the 
individual words or phrases does make sense but it is the deconstructive reading of the tailor that shows the actual meaning of Trotsky's message.

Few would deny that in the process of construing meaning, one is caught in the act of contextualizing - placing things in context (Goodwin and Duranti 1992; Dascal 2004b). ${ }^{1}$ In studying this act in any detail, it is unavoidable to notice the interaction of authorial intentions and context. Just consider the confusion that results from a lack of contextual information when, for example, you join a scheduled meeting half an hour late. Without the clues of the original context, you might find it hard to make sense of the ongoing discussion. In any case, the discussants would realise this and try to give you a quick rundown of the conversations so far. This is essentially the view of Clark and Carlson (1981) who regard context as information that is available to a person for interaction with a particular process on a given occasion. Their intrinsic context' is an attempt to capture the information available to a process that is potentially necessary for it to succeed. The intrinsic context for grasping what a speaker means on some occasion is the (limited) totality of the knowledge, beliefs, and suppositions that are shared by the speaker and the listener (also known as the 'common ground'). But, how does one really purport to know the intended meaning of a given message? It turns out that in his most recent volume of essays, Strawson expresses some views on this very question.

Strawson's book is entitled Entity and Identity, and the essays which treat the afore-mentioned question at some length appear as Chapters 11 and 12 (Strawson 1997a, 1997b). In these essays, ${ }^{2}$ Strawson advances a threefold distinction regarding how context bears on the meaning of 'what is said' when a sentence is uttered (Ziff 1972). In his view, three senses (sense-A-meaning, sense-B-meaning, and sense-C-meaning) capture increasingly more intricate and progressively richer aspects of what is said. But Strawson cautions that his proposed scheme may still be simplistic, since the situation may be more complicated than the scheme suggests, and raises various points to make it more adequate.

In this paper, we'll (i) review the original scheme of Strawson and summarize his improvements to his own scheme, and (ii) add our own suggestions to make it even more thoroughgoing. Overall, we'll defend the versatility of Strawson's framework. We'll also show that unless it is elaborated in several respects - mostly based on a viewpoint regarding context as a social construct (Akman 2000) and contextualizing as a form of social action (Fetzer and Akman 2002) - it cannot function as a realistic initiative towards building common sense models of how intended meaning is conveyed. ${ }^{3}$ 


\section{Strawson's scheme}

Clark and Carlson (1981) state that context has become a favourite word. They then complain that the denotation of the word has become murkier as its uses have been extended in many directions, making context some sort of 'conceptual garbage can'. Similar complaints can be sensed in some of the contributed chapters in Cole et al. (1997). In view of such grievances, Strawson's approach is commendable. He tackles the riddle of how context influences intended meaning by first proposing a simple question and an economic answer. He then attends to the complications that seem not to be easily resolvable by the latter.

Assume that a certain sentence S of a language L (e.g., English) was seriously uttered on some occasion. (The adverb "seriously" plays a crucial role, as we'll later see.) Assume further that X, the hearer, possesses only that much information: $\mathrm{X}$ knows that $\mathrm{S}$ was uttered but knows nothing about the identity of $Y$, the speaker, or the nature or date of the occasion. (In various places in the sequel, this restriction will be relaxed.) Let us grant $\mathrm{X}$ full mastery of the syntax and semantics of $\mathrm{L}$; thus, $\mathrm{X}$ is assumed to have ideally complete knowledge of $\mathrm{L}$ (lexicon plus grammar). The question is as follows (Strawson 1997a: 192):

[I]s there any sense in which $\mathrm{X}$ can be said to know the meaning of precisely what was said on the occasion in question?

Strawson's proposed scheme to analyse this problem consists in erecting three progressively richer senses of meaning, which he dubs sense-A-meaning, sense-B-meaning, and sense-C-meaning.

\subsection{Sense-A-Meaning}

Sense-A-meaning is linguistic meaning. Suppose $\mathrm{S}$ is free of ambiguity, or more realistically, $\mathrm{X}$ is informed which of the alternative readings of $\mathrm{S}$ is the right one, i.e., the one meant by Y. (It is beside the point, for the time being, how $\mathrm{X}$ could be told which of the possible lexical items or syntactic constructions $\mathrm{Y}$ actually had in mind in uttering $\mathrm{S}$.) We then say that $\mathrm{X}$ knows the sense- $A$ meaning of 'what is said'.

An important characteristic of such meaning is that if he has access to it, then $\mathrm{X}$ can give a correct translation of S into another language L' (e.g., French), which $\mathrm{X}$, once again, is assumed to know perfectly well. In other words, when sense-A-meaning is under consideration, $\mathrm{X}$ knows neither more nor less than what he needs to know in order to translate $S$ into a sentence $S^{\prime}$ of $\mathrm{L}^{\prime}$. 
Consider the following sentence: "The collapse of the bank took everyone by surprise". The designation of the word "bank" varies with different uses. Nevertheless, once the intended designation is clarified, then the translation of $\mathrm{S}$ from L to L' proceeds smoothly. Also witness Perry's similar remarks (Perry 1998: 2):

An ambiguous expression like 'bank' may designate one kind of thing when you say 'Where's a good bank?' while worried about finances, another when I use it, thinking about fishing. [...] Is the speaker holding a wad of money or a fishing pole?

To summarize the preceding paragraphs,

sense-A-meaning $\approx \mathrm{S} \oplus \mathrm{A}$-knowledge $\oplus$ disambiguating knowledge,

where A-knowledge is the ideally complete knowledge of the lexicon and grammar of $\mathrm{L}$. In this mock equation, the interpretations of $\approx$ and $\oplus$ are somewhat procedural; that is, the equation states that sense-A-meaning is obtained (approximated, if you will) by just understanding $S$ in the light of A-knowledge and disambiguating knowledge (and with a propensity toward accurate translation of $S$ into any other, equally rich language).

\subsection{Sense-B-Meaning}

Strawson's sense-B-meaning is linguistic-cum-referential meaning. $\mathrm{X}$ will learn the sense-B-meaning of $S$ if he has access to the references of proper names or indexicals that may be contained in S.

An example might illustrate the difference between sense- $A$ and sense- $B$ meanings. If $\mathrm{S}$ is the sentence "He stood on his head since then", and if $\mathrm{X}$ is further told that this potentially ambiguous sentence has its natural reading when "his" is co-referential with "he", then X can easily translate S to, say, French. When $\mathrm{X}$ does that accurately, it would show that X understood the sense-Ameaning of S. Now suppose X has no idea whom "he" stands for and which time point "then" denotes. This might not pose a problem for the translation. But if X additionally learns the reference of "he" (say, J.L. Austin) and "then" (say, New Year's Day, 1955) then X would know a richer meaning, the sense-B meaning of $S$.

In a style suggested by the earlier equation, sense-B-meaning $\approx$ sense-A-meaning $\oplus$ B-knowledge, 
where B-knowledge includes - in addition to A-knowledge - the knowledge of the reference of proper names and indexical expressions in S. Again, this mock equation can be interpreted as follows: sense-B-meaning is obtained by scrutinizing sense-A-meaning in the light of B-knowledge.

\subsection{Sense-C-Meaning}

Finally, Strawson offers sense-C-meaning as the complete meaning of a message. Sense-C-meaning is obtained by adding to sense-B-meaning the illocutionary force (à la Austin) of what was said, together with a complete grasp of how what was said is intended (by Y) to be understood (by X). Thus,

sense-C-meaning $\approx$ sense-B-meaning $\oplus \mathrm{C}$-knowledge,

where C-knowledge consists of - in addition to B-knowledge - the illocutionary force of $S$ plus the true intent of $\mathrm{Y}$. For instance, if $\mathrm{S}$ is the sentence "Don't sign that contract yet", then X needs to know whether this was issued as a request, a command, a piece of advice, or what have you. This is the dimension of meaning Austin captured with the phrase 'illocutionary force'.

There is a related but distinct notion: it may be that $\mathrm{Y}$ intends to be taken to be implying by $\mathrm{S}$ something that does not ensue from S's sense-B-meaning alone. Assume that $\mathrm{X}$ and $\mathrm{Y}$ know (and know each other to know) that their mutual friend $\mathrm{Z}$ declined an honour conferred upon him by the church. When Y says "It is the sign of a feeble mind to turn down a gift from God", the meaning of what he said would not be fully understood by $\mathrm{X}$ if $\mathrm{X}$ fails to recognize that $\mathrm{Z}$ is being labelled as the decrepit one by Y. Grice (1989) was the first to provide an elucidation of how a speaker can communicate more than what his words explicitly say. Since Strawson does cite Grice, it is safe to assume that he has in mind the same kind of systematic Gricean principles underlying pragmatic implication (Lindblom 2001).

\subsection{An inequality}

With the preceding three equations at hand, we can write the mock inequality sense-A-meaning $\leq$ sense-B-meaning $\leq$ sense-C-meaning,

where progressively richer senses of meaning are obtained by moving from left to right in the inequality. Since $\mathrm{X}$ employs (in proceeding from $\mathrm{S}$ to sense- $\mathrm{A}$, sense- $A$ to sense- $B$, and sense-B to sense-C) A-knowledge, B-knowledge, and 
C-knowledge, respectively, the progression in meaning will in general be additive. However, sometimes the move from one sense to another is really no move at all. A fitting example comes from mathematics: let $S$ be a sentence expressing a proposition of arithmetic, e.g., "There is always a prime number greater than a given natural number". In this case, the move from sense- $A$ to sense- $B$ is no move at all because the statement $S$ expresses an analytic truth.

What about C-knowledge? Can its contribution also be null sometimes? ${ }^{4}$ The answer is not in the affirmative, despite what Strawson thinks. To see this, take an explicitly performative statement such as "I order you to drop that gun". With Strawson, we may, at first, be inclined to accept that knowledge of the force of this $\mathrm{S}$ can be taken to belong to the sense-A-meaning. However, this is not really to follow Austin (1976). To give an example, if a mutinous private in the British army purported to order his sergeant to drop his gun and the cowardly sergeant did so, then a court martial would definitely rule that there was no order (or nothing with the force of an order), because a private cannot give an order to a sergeant. In other words, it is one thing for a type to be meant to be tokened in an act with a certain force and another thing for the token actually to realize an act with that force.

\subsection{Leech's Scheme}

Another threefold distinction due to Leech is worth indicating at this point. Leech states that specification of context has the effect of narrowing down the communicative possibilities of a message. He says that in particularizing meaning, context helps in the following ways (Leech 1981: 67):

(A) Context eliminates certain ambiguities or multiple meanings in the message (e.g., lets us know that page in a given instance means a boy attendant rather than a piece of paper).

(B) Context indicates the referents of certain types of word we call deictic (this, that, here, there, now, then, etc.), and of other expressions of definite meaning such as John, I, you, he, it, the man.

(C) Context supplies information which the speaker/writer has omitted through ellipsis (e.g., we are able to appreciate that Janet! Donkeys! means something like 'Janet! Drive those donkeys away!' rather than 'Janet! Bring those donkeys here!', or any other of the indefinitely many theoretical possibilities).

Clearly, (A) states the so-called disambiguating role of context and immediately brings to mind Strawson's sense-A-meaning. Likewise, (B) is along the lines of 
Strawson's sense-B-meaning. Finally, although the singling out of ellipsis might at first sight seem excessively specific, it is clear that Leech is talking in (C) about a particular way of how speaker's intention is to be inferred. His example has the same import as Strawson's sense-C-meaning, viz. the requirement that the reader must be aware of all that was intended by the speaker. "Janet! Donkeys!” is recurrently used by aunt Betsey Trotwood in David Copperfield; it is an order to her maid to carry out the routine task of driving donkeys off the grass.

Thus, context is seen to have a disambiguating function (among others). Consider the following conversation:

$\mathrm{X}$ (a woman, talking to $\mathrm{Y}$ ): "I am an investigator".

$\mathrm{Y}$ (talking to $\mathrm{Z}$ and referring to $\mathrm{X}$ ): "She is an investigator".

$\mathrm{Z}$ (talking to $\mathrm{X}$ ): "So, you are an investigator".

In this segment, the word 'investigator' has context-dependent meaning. The common ground of $\mathrm{X}, \mathrm{Y}$, and $\mathrm{Z}$ is used to select an appropriate meaning for this word. Similarly, the indexicals ('I' or 'she' or 'you') can be bound to the appropriate person (viz. X) only by the help of context. For example, the sentences uttered by $\mathrm{X}$ and $\mathrm{Y}$ have the same propositional content, and this we can say using some circumstantial information and conventions about discourse. To quote Recanati (1993: 235):

[T] he meaning of a word like 'I' is a function that takes us from a context of utterance to the semantic value of the word in that context, which semantic value (the reference of ' $\mathrm{I}$ ') is what the word contributes to the proposition expressed by the utterance.

\section{Dependence on context}

Having defined the three senses of meaning, A-, B-, and C-, Strawson turns to the following question: What specific differences are there in the ways in which the meaning of 'what is said' depends on context in the three cases? In particular, in which cases and to what degree can this dependence be itself represented as governed by linguistic rule or convention?

Obviously, context bears on the determination of sense-A-meaning in just those situations where $S$ suffers from syntactic and/or lexical ambiguity. However, disambiguation of $S$ by context at this level is not in general a matter of linguistic rule or convention. Rather, it is a matter of general relevance; see the earlier Perry's 'bank' example, above. In the same vein, Leech (1981: 69) states 
that it is relevant to the interpretation of "Shall I put the sweater on?" to know whether sweaters heated by electric power are on the market. This shows, in a rather strong sense, that the study of interpretation-in-context is closely tied to encyclopaedic knowledge about the world.

Context bears on the determination of sense-B-meaning in all cases except those where B-knowledge adds nothing to A-knowledge. And surely there are some semantic rules of natural language moderating such contextual dependence. Here's what Perry says about indexicals (Perry 1997: 597-598):

There is an intimate connection between the meanings of "I" and "the person who utters this token", even if it falls short of synonymy. The second phrase does not have the meaning of "I", but it gives part of the meaning of "I". It supplies the condition of designation that English associates with "I". [...] Here are the conditions of designation for some familiar indexicals [...]:

$\mathrm{I}: \mathrm{u}$ [an utterance of "I"] designates $\mathrm{x}$ iff $\mathrm{x}$ is the speaker of $\mathrm{u}$ you: $\mathrm{u}$ [an utterance of "you"] designates $\mathrm{y}$ iff $\exists \mathrm{x}$ ( $\mathrm{x}$ is the speaker of $\mathrm{u} \& \mathrm{x}$ addresses y with $u$ )

now: $u$ [an utterance of "now"] designates $t$ iff $\exists x(x$ is the speaker of $u \& x$ directs $\mathrm{u}$ at $\mathrm{t}$ during part of $\mathrm{t}$ )

that $\phi: \mathrm{u}$ [an utterance of "that $\phi$ "] designates $\mathrm{y}$ iff $\exists \mathrm{x}(\mathrm{x}$ is the speaker of $\mathrm{u} \&$ $\mathrm{x}$ directs $\mathrm{u}$ towards $\mathrm{y}$ )

It is noted, however, that B-knowledge is not wholly under the governance of language rules (cf. Perry's caveat: “... part of the meaning..."). For instance, with the demonstrative "here" there arises the question of how large a region to consider: "It is always very hot here at this time of the day". (In this room or in this town?)

Likewise, an utterance of "We must sell those HAL stocks now!" would signify different time points when it is made by a portfolio manager sitting at his on-line terminal ("now": in a couple of seconds) and by an executive during a luncheon with his assistants ("now": this afternoon).

\section{Amendments}

Strawson enumerated several points at which his threefold distinction is too crude to provide for all the complexities of language use. Despite the title of this section, he did not always suggest these as amendments to his scheme; sometimes he was content with just jotting them down. 


\subsection{Semantic creativity}

According to the inequality given earlier, some sense-A-meaning is always included in the complete meaning of 'what is said'. This is due to the nature of construction of sense-C-meaning. However, isn't it unrealistic to suppose that all meanings of a particular word are listed priorly in X's ideal lexicon? Consider the interpretation of a morphologically complex word w. Word formation rules might constrain but do not fully determine the interpretation of $\mathrm{w}$. To put it mildly, the linguistically specified meaning of w may and frequently does go beyond what is available from its compositional subparts (Chierchia and McConnell-Ginet 1990: 366-370).

Aitchison (1997: 16-17), for example, remarks that newspapers can popularize new words. Two recent examples are yomp and wimp. Yomp (to march with heavy equipment over difficult terrain) was a military term used frequently during the Falklands War. Wimp (an ineffectual person) originated in the U.S.; just remember a generic White House correspondent during the Gulf War: "President Bush has finally shaken off his wimp image".

Recanati uses the term contextual sense construction to refer to the general problem. He notes that sometimes the conventional sense of the subparts of a complex phrase and the way they are syntactically brought together is insufficient to evaluate the semantic value of the complex phrase. His examples are particularly forceful (Recanati 1994: 343):

Thus 'he finished the book' can mean that he finished reading the book, writing it, binding it, tearing it into pieces, burning it, and so forth [...]; 'finger cup' will mean either 'cup having the shape of a finger' or 'cup containing a finger of whisky' or 'cup which one holds with one finger', or whatever [...]; 'John's book' can mean 'the book that John owns, wrote, gave, received', or whatever [...]. In all such cases there is not a 'selection' from a limited range of preexisting interpretations for the complex phrase. Rather, an indefinite number of possible interpretations can be constructed in a creative manner. [our italics]

Strawson finds his scheme too simple when it comes to semantic creativity. A compromise can be made by allowing X's ideal dictionary be updated by adding the new (extended) meaning of a new word. However, he sees this as a sacrifice of his ground rules: when we do this, we make X's dictionary follow his understanding rather than his understanding obey his dictionary. 


\subsection{Seriousness}

Let us return to a crucial proviso in the original formulation - that $\mathrm{S}$ be seriously uttered. Seriousness and sincerity are closely related. Austin believes that for certain speech acts to be performed sincerely, a speaker must have the right thoughts or feelings; similarly, Searle thinks that for certain insincere speech acts a speaker pretends to have intentions or beliefs that she does not have (Mann and Kreutel 2004). This implies that an ironical utterance of S may be regarded as non-serious. However, ironical utterances make up quite a large crowd and cannot be so easily dismissed as aberrations.

The essential problem posed by ironical utterances is that a declarative sentence uttered ironically may express an idea that contradicts the idea that it professes to express. Consider saying "Oh, you are always so tidy!" to a janitor and meaning that he has made a mess again. Or imagine related variants like understatements, e.g., saying "It was rather concise" and meaning that it (say, a televised speech by the president) was extremely terse.

As Strawson (1997b: 222) notes, in these cases "we cannot say that the $\mathrm{C}$-meaning includes and adds to the B-meaning, but only that the C-meaning contradicts the apparent B-meaning". Figurative uses pose a similar problem. Harris (1996: 112) says:

If I say "Miller pulls off these tricks with string and sealing wax, false bottoms and sleight of hand", the statement will not be taken as figurative if I'm referring to an amateur magician, though it will be if the context makes it clear that I am referring to J.H. Miller the critical theorist.

\subsection{Reference}

Reference has always been a grand issue in studies of context in the philosophy of language, and it is only normal that Strawson notes that sometimes a given $S$ admits different interpretations where in one interpretation a certain constituent of S (e.g., a definite description) has a referential use whereas in some other interpretation it doesn't (Donnellan 1966; Kripke 1977). Let S be "The next parliamentary elections will resolve the matter. The descriptive phrase may be used to refer to a definite event (say, the elections scheduled to June 8, 2004) or S may be used with the intention of saying "Whensoever the parliamentary elections are carried out, the matter will be resolved'. 


\subsection{Translation proper}

An Italian saying, "Traduttore, traditore" (The translator is a betrayer), hints at the potential problems one can encounter in acquiring sense-A-meaning.

In an essay on translation, Jakobson (1992) distinguishes three ways of interpreting a verbal sign. Intralingual translation (rewording) interprets verbal signs by means of other signs of the same language. Interlingual translation (translation proper) interprets verbal signs by means of some other language. Finally, intersemiotic translation (transmutation) interprets verbal signs by means of signs of nonverbal sign systems. In order to demonstrate the difficulty of translation proper, he gives an example from Russian (Jakobson 1992: 148):

In order to translate accurately the English sentence "I hired a worker", a Russian needs supplementary information, whether this action was completed or not and whether the worker was a man or woman, because he must make his choice between a verb of completive or noncompletive aspect $[\ldots]$ and between a masculine and feminine noun [...]. If I ask the utterer of the English sentence whether the worker was male or female, my question may be judged irrelevant or indiscreet, whereas in the Russian version of this sentence an answer to this question is obligatory. On the other hand, whatever the choice of Russian grammatical forms to translate the quoted English message, the translation will give no answer to the question of whether I "hired" or "have hired" the worker, or whether he/she was an indefinite or definite worker ("a" or "the").

\subsection{Relevance}

Sperber and Wilson (1986) take relevance to be the psychological pertinence of a proposition to a context. The assumption is that people have intuitions of relevance, viz. they can consistently distinguish relevant from irrelevant information. However, these intuitions are not easy to elicit or use as evidence. Moreover, intuitions of relevance are relative to contexts, and there is no way of controlling exactly which context someone has in mind at a given moment. Despite these difficulties, Sperber and Wilson invoke intuitions of relevance. According to them, a proposition is relevant to a context if it interacts in a certain way with the (context's) existing assumptions about the world, i.e., if it has some contextual effects. These contextual effects include:

- Contextual implication: A new assumption can be used together with the existing rules in the context to generate new assumptions; 
- Strengthening: A new assumption can strengthen some of the existing assumptions;

- Contradicting or eliminating: A new assumption may change or eliminate some of the existing assumptions of the context.

Sperber and Wilson talk about degrees of relevance. Clearly, one piece of information may be more relevant to a particular context than to another. To compare the relevance of pieces of information, they consider the mental processing effort, e.g., the length of the chain of reasoning and the amount of encyclopaedic information involved, and so on. Finally, they propose a celebrated maxim (Sperber and Wilson 1986: 125), which we can summarize as follows:

The Relevance Maxim: An assumption is relevant in a context to the extent that its contextual effects in this context are large. Conversely, an assumption is irrelevant in a context to the extent that the effort required to process it in this context is large.

The measurement of contextual effects and processing effort is a difficult task due to the problems of qualification of mental effects and effort, Sperber and Wilson warn (1986: 130):

The problems involved in measuring contextual effects and processing effort are, of course, by no means specific to relevance theory or to pragmatics. They affect psychology as a whole. However, for relevance theory these problems take on a more specific form. Within relevance theory, the problem is not so much to assess contextual effects and processing effort from the outside, but to describe how the mind assesses it own achievements and efforts from the inside, and decides as a result to pursue its efforts or relocate them in different directions.

\section{Further points}

The following are not so much weaknesses of Strawson's scheme as possible avenues of research for streamlining it.

\subsection{Radical interpretation and presemantic uses}

Regarding sense-A-meaning, the following singularity needs to be noticed: If his A-knowledge is null then $\mathrm{X}$ cannot even set himself to the study the question properly. This remark should not be taken as an avowal of the impossibility of radical interpretation. When $\mathrm{X}$ is a radical interpreter who must interpret $\mathrm{L}$ 
from scratch, he must do so in the absence of any antecedent understanding of $\mathrm{L}$, and only using evidence that is plausibly available to him (Davidson 1984).

That this is difficult, on the other hand, is something even Davidson himself accepts to a large extent (Kent 1993):

It would beg the question, in trying to study the nature of interpretation, to assume that you know in advance what a person's intentions, beliefs, and desires are. [...] There is no master key or framework theory that you can have prior to a communicative interaction or situation.

Sometimes context is used to figure out which language is being spoken. Consider a well-known example due to Perry (2000: 314):

Ich! (said by several teenagers at camp in response to the question, "Who would like some sauerkraut?")

Perry says that knowing that this took place in a German rather than an American camp might help one to see that it was made by eager German teenagers rather than American teenagers repelled by the very idea. In this case, context (or rather its presemantic use) is pertinent to figuring out which language is being used.

\subsection{Contextual domains and subjective adjectives}

A discussion given by Recanati (1998) refers to the fact that natural language quantifiers often seem implicitly restricted. When $S$ is the sentence "The president shook hands with everyone", $\mathrm{X}$ is inclined to think that "everyone" must range over the domain of people who attended the press conference or the reception or the fund-raising dinner or whatever - not everyone in the whole world. Along similar lines, when Y utters "Most beggars attended the bash" he is likely to allude to a particular group of beggars (say, those in his neighbourhood); it is from this group that many joined the festivities.

In dealing with subjective (relative) adjectives such as "large", the context contributes to meaning in a decisive way. Consider this (Chierchia and McConnell-Ginet 1990: 374): "Lee built a large snowman". If Lee is a toddler playing in the backyard of his house, the snowman is probably at most as big as Lee himself. On the other hand, if Lee is a teenager competing in a snow carnival, the snowman is probably much bigger than Lee.

One way of dealing with the context-dependent nature of relative adjectives is to assume that the context provides us with a set of comparison classes. Still, with sentences like "A large tadpole is not a large animal", the problem remains 
unresolved. In the same context, different comparison classes are needed for the first and second occurrences of the adjective.

\subsection{Context renewal}

Consider an on-going conversation between $\mathrm{X}$ and $\mathrm{Y}$. $\mathrm{Y}$ utters $\mathrm{S}, \mathrm{X}$ in return utters $S^{\prime}, Y$ in return utters $S^{\prime \prime}$, and so on and so forth. In order to understand say, $S^{\prime \prime}, X$ would need to use the previous discourse, or the meaning of 'what was said earlier.' That an interactional context is continually being developed with each successive utterance is an observation Heritage (1984) has made in his work on ethnomethodology. According to him, utterances and the social actions they embody are treated as doubly contextual. First, utterances and actions are context-shaped. This means that their contributions cannot be adequately appreciated unless the context in which they operate is taken into account. Second, utterances and actions are context-renewing. Every utterance will form the subsequent context for some following action in a sequence; it will thus contribute to the contextual framework that lets one understand the next action. Additionally, each action will function to renew context, where renewal is understood as one or more of the processes of maintaining, adjusting, altering, and so on. In the remainder of this section, we look at contributions similar in nature to Heritage's. Our general point is that at the level of sense-Cmeaning Strawson's scheme would benefit from enhancements of sociocultural nature. $^{5}$

\subsection{Communicative competence}

Gumperz (1997: 40-41) regards communicative competence as "the knowledge of linguistic and related communicative conventions that speakers must have to initiate and sustain conversational involvement". This requires knowledge of social and cultural rules of a language - in addition to a knowledge of grammatical - and preferably addresses the competences of actual speakers, not an idealized standard. In (Gumperz 1992), he introduces what is known as a contextualization cue. He confirms that a given aspect of linguistic behaviour (e.g. lexical, prosodic, phonological, etc.) can function as a cue, indicating those aspects of context that are to be taken into account to interpret what is said by a speaker. Contextualization cues hint at relevant aspects of the social context (via particular codes, styles, and dialects), thus enabling participants in a discourse to reason about their respective communicative intentions 
and purposes. He also notes that because of its cultural base, the meaning of a conversation is frequently different for different participants if they are not members of the same speech community. In (Gumperz 1993), he offers a case study of how a difference in the use of contextualization cues between a native speaker of English and a non-native yet fluent speaker of English causes a serious breakdown in communication.

Another example of a cross-cultural communicative event is the following exchange in a kindergarten on a reservation (Saville-Troike 1989: 131-132):

A Navajo man opened the door to the classroom and stood silently, looking at the floor. The Anglo-American teacher said 'Good morning' and waited expectantly but the man did not respond. The teacher then said 'My name is Mrs. Jones,' and again waited for a response. There was none.

The whole exchange is more enlightening but this brief excerpt illustrates our point. The man's silence is appropriate from a Navajo perspective; it shows respect. What is more, a religious Navajo taboo prohibits individuals from saying their own name. Mrs. Jones's expectation is also reasonable from an AngloAmerican perspective; the man must have returned her greeting, identified himself, and stated his reason for being there. It turns out that he was there to take his son, Billy, and that Billy is more accustomed to the Anglo-American ways than his stoic father is: as he walks towards his father, he waves at Mrs. Jones and says 'Bye-bye'.

\section{Conclusion}

The originator of a message usually assumes quite a bit of background knowledge on the part of an addressee (Leech 1981: 66). The task of the addressee is to narrow down the list of meanings available to him and attain the intended meaning. Originally, the message may be replete with several potential meanings. By enveloping it in increasingly narrower contexts, the number of meanings is reduced (Dascal 2004a). Eventually, it is hoped that just one meaning is isolated as the meaning of the message. ${ }^{6}$

This paper argued that there is a certain persuasive approach to studying the feasibility of this problem, first spelled out in "Austin and 'locutionary meaning" and later taken up in detail in "Meaning and context," two early papers by Strawson. The approach is both simple and elegant, and we believe that future studies to formalize context (Akman and Surav 1996, 1997) might profit from its formulaic nature. ${ }^{7}$ 


\section{Notes}

* An earlier and shorter version of this paper was presented in CONTEXT'99 (Akman and Alpaslan 1999) and benefited from the perceptive remarks of the anonymous referees of that conference. Some of their comments are utilized verbatim in a couple of places in this paper. Insightful remarks of the anonymous referees of Pragmatics \& Cognition have also been very helpful. As for our reconstruction of Strawson's ideas, we hope that our interpretation and (partial) reworking of his work is accurate. However, as Johnson-Laird (1990: 9) rightly cautions: "[T]here is no end to the process of recovering speakers' intentions - why they chose to communicate this or that information. And a text does not talk back, and hence as its author's background assumptions fade into obscurity so its interpreters are free to project ever wider and ever more idiosyncratic readings into it".

1. Modern literary theory distinguishes between an author's intended meaning and whatever significances a reader finds in the text. Not all patterns and relationships found by the reader in a text can be attributed to authorial intentions. The producer of a text, Eco (1984: 7) claims, "has to foresee a model of the possible reader [...] supposedly able to deal interpretatively with the expressions in the same way as the author deals generatively with them". This possible reader Eco calls the model reader. In order to make his text communicative, the author has to make sure that the totality of 'codes' upon which his work is built is the same as that shared by the model reader.

2. The original essays were published considerably earlier. Thus, Chapter 11, "Austin and 'locutionary meaning"', first appeared in I. Berlin et al. (eds), 1973, Essays on J.L. Austin. Oxford: Oxford University Press. A partial translation of Chapter 12, "Meaning and context," appeared in 1970 in Langages 17, with the title "Phrase et acte de parole".

3. An explanation regarding the motivations of the two essays is in order. Austin (1976) famously distinguished between the meaning and the force of an utterance. He associated the former with the 'locutionary' act performed in making the utterance, and the latter with the 'illocutionary' act. In his chapter on Austin, Strawson uses the threefold distinction to examine Austin's work; his standpoint is that what Austin means by locutionary meaning is not very clear. On the other hand, in "Meaning and context" the threefold distinction itself is examined in detail. Our remarks will generally bear on the contents of this essay.

4. One may object to the preceding analysis by noting that there are naturally occurring contexts in which the particular $S$ of this example might have a metaphorical meaning. At least, this is exactly what happens when one replaces S with a similar sentence, "He stood on his own feet since then", meaning: He thought and acted independently since then. We agree and note that this is precisely the point of Strawson's imposition, viz. S is uttered seriously. More on this later.

5. In which case the move from $\mathrm{B}$ to $\mathrm{C}$ might still be regarded as an addition, even if it is the minimal addition that there is nothing to be added to the B-meaning.

6. See Fetzer and Akman (2002) and Fetzer (2004) for recent work on social aspects of context. 
7. While this would definitely require another, full-fledged treatment elsewhere, it must be noted that via his ingenious construct grafting, Derrida has argued against this possibility. With this term he refers to the process of inserting an utterance onto a context that alters its functioning (or imagining a context in which an initially meaningless sentence would have meaning). For Derrida, context is infinitely expandable. And while meaning is context-bound, context is boundless. Sympathizing with Derrida, Culler (1988:148) mentions a court case, Frigaliment vs. BNS International Sales Corp., where several witnesses were summoned to confirm what chicken meant in the chicken trade: a bird of any age or a young broiler, fryer, or roaster? The lawyers involved in the case knew that context is produced, and that since context is not saturable, a contextualization is never completed (Edmonds and Akman 2002).

8. One of the referees suggested that a hearer in a situation should consider, instead of the framework proposed in this paper, constructing a full model of what is going on and then alter it if it proves to be unhelpful in understanding/communicating. The model might involve, it was suggested, all kinds of factors (lexical, deictic, contextual, etc.), although not necessarily structured in any specific way, as the present work (or rather, Strawson) suggests. We think that this is also a viable (and admittedly, rather different) approach. In any case, it is clear, as the referee observes, that the threefold Strawsonian scheme is not linear or unidirectional, e.g., sense-B-meaning can influence sense-A-meaning. Now, does the presence of such interaction among senses prove that the scheme is totally undermined? We do not believe so, although we appreciate the caveat of the referee.

\section{References}

Aitchison, J. 1997. The Language Web: The Power and Problem of Words. Cambridge: Cambridge University Press.

Akman, V. 2000. "Rethinking context as a social construct". Journal of Pragmatics 32(6): 743-759.

Akman, V. and Alpaslan, F.N. 1999. "Strawson on intended meaning and context". In P. Bouquet, L. Serafini, P. Brézillon, M. Benerecetti, and F. Castellani (eds), Modeling and Using Context (Proceedings of CONTEXT'99). Berlin: Springer, 1-14.

Akman, V. and Bazzanella, C. 2003. “The complexity of context: Guest editors' introduction”. Journal of Pragmatics 35(3): 321-329.

Akman, V. and Surav, M. 1996. "Steps toward formalizing context". AI Magazine 17(3): $55-72$.

Akman, V. and Surav, M. 1997. "The use of situation theory in context modeling". Computational Intelligence 13(3): 427-438.

Austin, J.L. 1976. How to Do Things with Words. J.O. Urmson and M. Sbisà (eds). Oxford: Oxford University Press.

Chierchia, G. and McConnell-Ginet, S. 1990. Meaning and Grammar: An Introduction to Semantics. Cambridge, MA: The MIT Press.

Clark, H.H. and Carlson, T.B. 1981. "Context for comprehension". In J. Long and A. Baddeley (eds), Attention and Performance IX. Hillsdale, NJ: Lawrence Erlbaum, 313-330. 
Cole, R., Mariani, J., Uszkoreit, H., Zaenen, A., and Zue, V. (eds). 1997. Survey of the State of the Art in Human Language Technology. New York: Cambridge University Press.

Culler, J. 1988. "Deconstruction and the law". In his Framing the Sign: Criticism and Its Institutions. Oxford: Blackwell, 139-152.

Dascal, M. 2004a. "Cues, clues, and context". In Interpretation and Understanding. Amsterdam: John Benjamins, 169-193.

Dascal, M. 2004b. "Contextualism". In Interpretation and Understanding. Amsterdam: John Benjamins, 542-561.

Davidson, D. 1984. "Radical interpretation". In Inquiries into Truth and Interpretation. Oxford: Clarendon Press, 125-139.

Donnellan, K. 1966. "Reference and definite descriptions". Philosophical Review 75(3): 281304.

Eco, U. 1984. The Role of the Reader: Explorations in the Semiotics of Texts. Bloomington, IN: Indiana University Press.

Edmonds, B. and Akman, V. 2002. "Editorial: Context in context". Foundations of Science 7(3): 233-238.

Fetzer, A. 2004. Recontextualizing Context: Grammaticality Meets Appropriateness. Amsterdam: John Benjamins.

Fetzer, A. and Akman, V. 2002. "Contexts of social action: Guest editors' introduction". Language and Communication 22(4): 391-402.

Goodwin, C. and Duranti, A. 1992. "Rethinking context: An introduction". In A. Duranti and C. Goodwin (eds), Rethinking Context: Language as an Interactive Phenomenon. Cambridge: Cambridge University Press, 1-42.

Grice, P.H. 1989. Studies in the Way of Words. Harvard, MA: Harvard University Press.

Gumperz, J. 1992. "Contextualization and understanding". In A. Duranti and C. Goodwin (eds), Rethinking Context: Language as an Interactive Phenomenon. Cambridge, UK: Cambridge University Press, 229-252.

Gumperz, J. 1993. “Culture and conversational inference”. In W.A. Foley (ed), The Role of Theory in Language Description. Berlin: Mouton de Gruyter, 193-214.

Gumperz, J. 1997. "Communicative competence". In N. Coupland and A. Jaworski (eds), Sociolinguistics: A Reader and Coursebook. Houndmills, UK: Macmillan, 39-48.

Harris, W. 1996. Literary Meaning: Reclaiming the Study of Literature. Houndmills, UK: Macmillan.

Heritage, J. 1984. Garfinkel and Ethnomethodology. Cambridge: Polity Press.

Jakobson, R. 1992. “On linguistic aspects of translation". In R. Schulte and J. Biguenet (eds), Theories of Translation: An Anthology of Essays from Dryden to Derrida. Chicago: The University of Chicago Press, 144-151.

Johnson-Laird, P. 1990. “Introduction: What is communication?". In D.H. Mellor (ed), Ways of Communicating. Cambridge: Cambridge University Press, 1-13.

Kent, T. 1993. "Language philosophy, writing, and reading: A conversation with Donald Davidson". Journal of Advanced Composition 13(1): 1-20. Available online at http://jac. gsu.edu/jac/13.1/Articles/1.htm

Kripke, S. 1977. "Speaker's reference and semantic reference". In P.A. French, T. Uehling, Jr., and H.K. Wettstein (eds), Contemporary Perspectives in the Philosophy of Language, Minneapolis, MN: University of Minnesota Press, 6-27. 
Leech, G. 1981. Semantics: The Study of Meaning. Harmondsworth, UK: Penguin.

Lindblom, K. 2001. "Cooperating with Grice: A cross-disciplinary metaperspective on uses of Grice's cooperative principle". Journal of Pragmatics 33(10): 1601-1623.

Lyons, J. 1995. Linguistic Semantics: An Introduction. Cambridge: Cambridge University Press.

Mann, W. and Kreutel, J. 2004. "Speech acts and recognition of insincerity". In Proceedings of the Eight Workshop on the Semantics and Pragmatics of Dialogue (CATALOG'04), Universitat Pompeu Fabra, Barcelona. Available online at http://www.upf.edu/dtf/personal/enricvallduvi/catalog04/papers/09-mann-kreutel.pdf

Perry, J. 1997. "Indexicals and demonstratives". In B. Hale and C. Wright (eds), A Companion to the Philosophy of Language. Oxford: Blackwell, 586-612.

Perry, J. 1998. "Indexicals, contexts, and unarticulated constituents". In A. Aliseda, R. van Glabbeek, and D. Westerståhl (eds), Computing Natural Language. Stanford, CA: CSLI Publications, 1-11.

Perry, J. 2000. "What are indexicals?". In The Problem of the Essential Indexical (and Other Essays). Stanford, CA: CSLI Publications, 313-323.

Recanati, F. 1994. "Processing models for non-literal discourse". In R. Casati, B. Smith, and G. White (eds), Philosophy and the Cognitive Sciences. Vienna: Hoelder-Pichler-Tempsky, 343-356.

Recanati, F. 1998. “Contextual domains”. In X. Arrazola, K. Korta, and F.J. Pelletier (eds), Discourse, Interaction, and Communication. Amsterdam: Kluwer, 25-36.

Saville-Troike, M. 1989. The Ethnography of Communication: An Introduction. Oxford: Blackwell.

Scharfstein, B.-A. 1989. The Dilemma of Context. New York: New York University Press.

Sperber, D. and Wilson, D. 1986. Relevance: Communication and Cognition. Oxford: Basil Blackwell.

Strawson, P.F. 1997a. "Austin and 'locutionary meaning"' In his Entity and Identity (and Other Essays). Oxford, UK: Clarendon Press, 191-215.

Strawson, P.F. 1997b. "Meaning and context". In his Entity and Identity (and Other Essays). Oxford, UK: Clarendon Press, 216-231.

Ziff, P. 1972. "What is said". In D. Davidson and G. Harman (eds), Semantics of Natural Language. Dordrecht: D. Reidel, 709-721.

\section{Author's address}

Varol Akman

Department of Philosophy

Bilkent University

Bilkent, Ankara 06800

Turkey

Email: akman@bilkent.edu.tr 


\section{About the author}

Varol Akman is chair of the Department of Philosophy and a professor in the Department of Computer Engineering at Bilkent University, Ankara. Before joining Bilkent, he held visiting positions with Centrum voor Wiskunde en Informatica (1986-88) and Universiteit Utrecht (1985-86), both in the Netherlands. During the period 1980-85, he was a Fulbright scholar at Rensselaer Polytechnic Institute, New York, where he received a Ph.D. degree in computer engineering. His current work is in the following areas: situation theory and situation semantics; logic and contextual reasoning; semantics and pragmatics of indexicals; social implications of the Internet. 